\title{
BMJ Open Pre-hospital anaesthesia and assessment of head injured patients presenting to a UK Helicopter Emergency Medical Service with a high Glasgow Coma Scale: a cohort study
}

Duncan Bootland, ${ }^{1,2}$ Caroline Rose, ${ }^{1}$ Jack W Barrett, ${ }^{3}$ Richard Lyon, ${ }^{1,4}$ on behalf of Kent, Surrey \& Sussex Air Ambulance Trust

To cite: Bootland D, Rose C, Barrett JW, et al. Pre-hospital anaesthesia and assessment of head injured patients presenting to a UK Helicopter Emergency Medical Service with a high Glasgow Coma Scale: a cohort study. BMJ Open 2019;9:e023307. doi:10.1136/ bmjopen-2018-023307

\section{- Prepublication history for} this paper is available online. To view these files, please visit the journal online (http://dx.doi. org/10.1136/bmjopen-2018023307).

Received 8 April 2018 Revised 6 November 2018 Accepted 21 December 2018

D) Check for updates

C Author(s) (or their employer(s)) 2019. Re-use permitted under CC BY-NC. No commercial re-use. See rights and permissions. Published by BMJ.

${ }^{1}$ Kent, Surrey and Sussex Air Ambulance, Redhill, UK ${ }^{2}$ Emergency Department, Royal Sussex County Hospital, Brighton, UK

${ }^{3}$ South East Coast Ambulance Service NHS Foundation Trust, Banstead, UK

${ }^{4}$ Department of Health Sciences, University of Surrey, Guildford, UK

Correspondence to Dr Richard Lyon; richardlyon@doctors.org.uk

\section{ABSTRACT}

Objectives Patients who sustain a head injury but maintain a Glasgow Coma Scale (GCS) of 13-15 may still be suffering from a significant brain injury. We aimed to assess the appropriateness of triage and decision to perform prehospital rapid sequence induction (RSI) in patients attended by a UK Helicopter Emergency Medical Service (HEMS) following head injury.

Design A retrospective cohort study of patients attended by Kent Surrey \& Sussex Air Ambulance Trust (KSSAAT) HEMS.

Setting A mixed urban and rural area of 4.5 million people in South East England.

Participants GCS score of 13,14 or 15 on arrival of the HEMS team and clinical findings suggesting head injury. Patients accompanied by the HEMS team to hospital ('Escorted'), and those that were 'Assisted' but conveyed by the ambulance service were reviewed. No age restrictions to inclusion were set.

Primary outcome measure Significant brain injury. Secondary outcome measure Recognition of patients requiring prehospital anaesthesia for head injury.

Results 0 517 patients, 321 had adequate follow-up, $69 \%$ of these were Escorted, $31 \%$ Assisted. There was evidence of intracranial injury in $13.7 \%$ of patients and clinically important brain injury in $7.8 \%$. There was no difference in the rate of clinically important brain injury between Escorted and Assisted patients ( $p=0.46$ ). Nineteen patients required an RSI by the HEMS team and this patient group was significantly more likely to have clinically important brain injury $(p=0.04)$.

Conclusion In patients attended by a UK HEMS service with a head injury and a GCS of 13-15, a small but significant proportion had a clinically important brain injury and a proportion were appropriately recognised as requiring prehospital RSI. For patients deemed not to need a HEMS intervention, differentiating between those with and without clinically important brain injury appears challenging.

Level of evidence $V$.

\section{BACKGROUND}

Head injury and neurotrauma account for significant mortality, and serious morbidity.
Strengths and limitations of this study

- This is a retrospective study relying on contemporaneously collected data.

- The population covered includes a rural and urban population.

- There was incomplete follow-up data and this was particularly marked in the patients not transferred to hospital by the Helicopter Emergency Medical Service team.

- Despite the statistical differences shown, comparisons were between small and disproportionate data-sets.

- We included patients who suffered head injuries plus additional insults, which may have influenced the decision-making of the attending teams regarding triage and choice of interventions.

Approximately 200000 people are admitted to hospital with head injury in the UK every year. Of these patients, $95 \%$ present with a normal or minimally impaired conscious level (Glasgow Coma Scale (GCS) score greater than 12). ${ }^{1}$ The Glasgow Coma Scale is used to classify traumatic brain injury (TBI) into levels of severity and prognosis. Mild or minor TBI (mTBI) is classified as GCS 13-15 after head injury. ${ }^{2}$ Abnormalities on CT scans in patients with mild head trauma are relatively common, although the need for neurosurgical intervention is rare. ${ }^{3}$ Of all TBI's, $90 \%$ are considered mild, with full recovery to normal functional status almost certain. Intracranial complications of mTBI are infrequent $(10 \%)$, requiring neurosurgical intervention in a small minority of cases $(1 \%) .{ }^{4}$ Most patients who attend hospital after a head injury do not develop life threatening or disabling complications in the acute stage. However, in a small group of patients, 
outcome is worsened by a failure to promptly and accurately detect possible complications and intervene accordingly. ${ }^{156}$ In the UK, the first hour following trauma is usually spent in the prehospital phase,${ }^{78}$ meaning that triage and management decisions, including allocation of resources, falls to prehospital clinicians with limited immediate access to diagnostic tools. All traumatic incidents are attended by the local ambulance service (South East Coast Ambulance Service). When clinical need of a patient suggests enhanced medical care may be required, a regional Helicopter Emergency Medical Service (HEMS) exists.

Previous studies in the UK and Canada ${ }^{9}{ }^{10}$ have shown that patients, both in the prehospital environment and in emergency department (ED) who had sustained a head injury with a GCS of 13-15 could still be suffering from significant brain injury. However, there is little published data regarding the appropriate management and triage of patients following head trauma.

We aimed to assess the appropriateness of triage and medical escort decisions together with the decision to perform prehospital rapid sequence induction (RSI) by a UK HEMS team when treating head injured patients with normal or mildly impaired consciousness.

\section{METHODS}

\section{Study cohort}

Kent, Surrey \& Sussex Air Ambulance Trust (KSSAAT) delivers care to a mixed urban and rural area, covering 4.5 million people across the south east of England. The HEMS team comprises an experienced physician and paramedic capable of delivering enhanced care, including RSI of anaesthesia, chest thoracostomy, blood product administration and procedural sedation. These interventions cannot be routinely performed by land ambulance crews. The HEMS service operates from two separate bases, responds $24 / 7$ and can respond in either a helicopter or response car, depending on geography and weather limitations. Major trauma patients are transported to hospital either by helicopter or land ambulance. Whether the HEMS team also accompanies the patient to hospital, in addition to the land ambulance crew, is made on clinical grounds. During the study period, the HEMS team was dispatched to scene by a HEMS paramedic reviewing incoming calls to the ambulance dispatch centre.

Retrospective data, including hospital follow-up data recorded routinely by the service, was collected from the KSSAAT electronic database between 1 January 2015 and 31 December 2015. All data were anonymised and only clinically relevant data were reviewed.

Inclusion criteria were a patient attended by KSSAAT HEMS; an initial GCS score of 13, 14 or 15 on arrival of the HEMS team and clinical history or examination suggesting head injury. Exclusion criteria included the patient suffering a primary medical (non-traumatic) incident; patients suffering major haemorrhage which could alter conscious level; major burns and patients with an incomplete data-set. No age restrictions to inclusion were set.

Patients were divided into two groups:

1. Patients transported to hospital accompanied by the HEMS team. Accompanied patients, transported via helicopter or ground transfer, were classed as an 'Escort'. The decision to transfer patients by ground or air was usually in respect to the current weather conditions or time of day (although KSSAAT fly at night, night landing at hospital was significantly limited during the period of study), rather than the patient's clinical need. Patients that received an RSI were classed as 'RSI' and were included in the Escort cohort, but were also subsequently separated for appropriate analysis.

2. Patients where the HEMS team attended and assisted the ground crew but did not accompany the patient to hospital; this was classed as an 'Assist'.

Within each group, CT scan reports were collected, those that included the head were analysed and considered abnormal according to the radiologist reports. Abnormality of CT scan was defined as intracranial trauma demonstrated by a radiologist's report confirming skull fracture and/or intracranial bleeding. In order to assess the clinical relevance of any injury seen on CT we further defined a group of patients with "clinically important' brain injury. This classification was a combination measure of that described by Stiell et al (solitary contusion $>5 \mathrm{~mm}$, localised subarachnoid blood $>1 \mathrm{~mm}$, smear of subdural haematoma $>4 \mathrm{~mm}$, isolated pneumocephaly, or closed depressed skull fracture not through the inner table $)^{10}$ plus any evidence in the follow-up notes of neurosurgical intervention. To avoid underestimation of the extent of the injury, intracranial injury on CT scan was deemed clinically important unless there was confirmatory evidence that this was not the case.

\section{Patient and public involvement}

Patient data are routinely collected by KSSAAT as part of standard, routine care. Patient input into ongoing audits and research is sought through the South East Coast Ambulance Service research and development committee, which has layperson representation. Lay representation on the KSSAAT charity board, expressed support for further research being undertaken into TBI. Patients were not directly involved in the design of this study but the results and impact are shared directly with the lay representatives.

\section{Analysis}

The analysis included the type of incident attended, the mechanism of the injury (blunt or penetrating) and if HEMS were needed (defined as performing an intervention available only to the HEMS enhanced care team, box 1). Isolated head injuries were defined as any clinical record which recorded the head as the only area of injury. Any head injury with a fracture or injury below the head was deemed multiple trauma. Data were also collected on 
Box 1 Helicopter Emergency Medical Services clinical interventions

- Prehospital rapid sequence induction of anaesthesia.

- Ketamine for sedation.

- Midazolam for sedation.

Transfusion of blood products.

Polytrauma with need to bypass trauma unit beyond $45 \mathrm{~min}$.

how many patients went to major trauma centres (MTCs) and trauma units (TUs). TUs are receiving hospitals but without access to all trauma specialities, specifically without on-site neurosurgery. Change in clinical condition during transfer to hospital and whether a HEMS intervention was required were also reviewed.

CT findings were compared in patients requiring HEMS RSI, those kept awake and between Escort and Assist patients. Triage to MTCs and TUs were also compared.

\section{Statistical analysis}

Cross-tabulation was used to analyse differences between categorical data ( $\mathrm{X}^{2}$ and Fishers Exact, where applicable) and a Mann-Whitney $U$ test was used to measure differences in continuous data; statistical significance was set at $\mathrm{p} \leq 0.05$. All analysis was performed on SPSS (IBM, V.23) for Windows.

\section{RESULTS}

Over the study period, 1875 patients were seen by KSSAAT HEMS. A total of 517 patients met inclusion criteria, of which 321 patients had adequate follow-up. Table 1 summarises the cohort examined. The majority of patients were male $(74 \%)$, with an average age of 43 years. Overall, $96 \%$ of injuries were the result of blunt trauma, with road traffic collisions accounting for $58 \%$ of all incidents. Thirty per cent were accidental injuries with the remainder split between assaults, intentional

\section{Table 1 Comparison between the Assisted and Escorted cohorts}

\begin{tabular}{|c|c|c|c|}
\hline & Assist & Escort & $P$ value \\
\hline Total patients & 232 & 285 & \\
\hline Data available & 98 & 223 & 0.01 \\
\hline Sex male (\%) & $72(73)$ & $167(75)$ & 0.72 \\
\hline Age $( \pm S D)$ & $40(23)$ & $44(22)$ & 0.27 \\
\hline Trauma blunt (\%) & $95(97)$ & $214(96)$ & 0.67 \\
\hline Multiple trauma (\%) & $65(66)$ & $184(83)$ & 0.01 \\
\hline Isolated head trauma (\%) & $33(34)$ & $39(17)$ & 0.01 \\
\hline Accidental injury (\%) & $25(26)$ & $71(32)$ & 0.23 \\
\hline Assault (\%) & $4(4)$ & $11(5)$ & 0.49 \\
\hline Intentional self-harm (\%) & 0 & $7(3)$ & - \\
\hline Road Traffic Collision (\%) & $61(62)$ & $125(56)$ & 0.30 \\
\hline Sport/leisure (\%) & $8(8)$ & $9(4)$ & 0.12 \\
\hline Abnormal CT (\%) & $17(17)$ & $69(31)$ & 0.01 \\
\hline Intracranial trauma (\%) & $16(16)$ & $58(26)$ & 0.05 \\
\hline Clinically important injury (\%) & $6(6)$ & $19(9)$ & 0.46 \\
\hline MTC (\%) & $51(52)$ & $194(87)$ & 0.01 \\
\hline TU (\%) & $47(48)$ & $29(13)$ & 0.01 \\
\hline HEMS needed? (\%) & $16(16)$ & $68(30)$ & 0.01 \\
\hline Deterioration to hospital & 0 & 0 & - \\
\hline RSI in ED (\%) & $2(2)$ & $16(7)$ & 0.61 \\
\hline pH RSI (\%) & - & $19(9)$ & - \\
\hline Abnormal CT (\%) & - & $12(5)$ & - \\
\hline Intracranial trauma & - & $12(5)$ & - \\
\hline Clinically important injury & - & $6(3)$ & - \\
\hline
\end{tabular}

Values are number of patients (percentage of the total number, unless otherwise stated). Where $p$ values are omitted data were insufficient to provide meaningful comparison.

ED, emergency department; HEMS, Helicopter Emergency Medical Service; MTC, major trauma centre; RSI, rapid sequence induction; TU, trauma centre. 


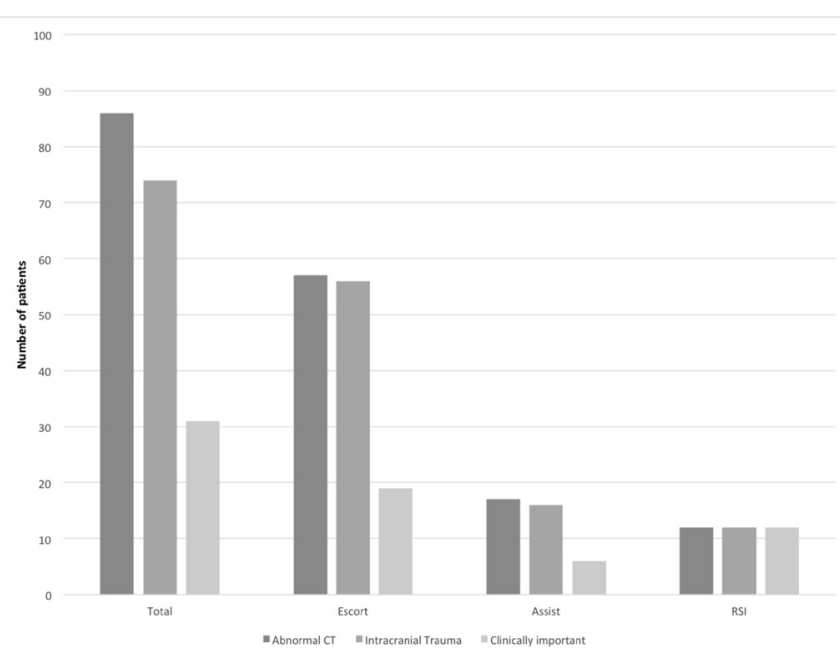

Figure 1 Incidence of abnormal CT, the presence of intracranial trauma and the need for neurosurgery. Values are number of patients. RSI, rapid sequence induction.

self-harm and sport/leisure activities. The mean transit time to hospital from scene for the Escorted group was 37 min (range 4-127 min).

\section{Triage to hospital}

The majority $(87 \%)$ of patients in the Escort cohort were conveyed to an MTC whereas in the Assist group the conveyance was equal between MTC (52\%) and TU $(48 \%)$ (table 1). Patients that were assisted and left to be transported by non-HEMS crews were more likely to be conveyed to a TU compared with the Escorted cohort $(\mathrm{p}=0.01)$.

\section{Assisted versus escorted patients}

The HEMS team escorted 223 patients to hospital (69\%, 'Escort') whereas 98 patients were taken to hospital by the ambulance service without the HEMS team (31\%, 'Assist'). In patients who did not receive pre-hospital RSI, abnormal CT was higher in the Escorted cohort $(n=57$, $28 \%)$ compared with the Assisted cohort $(\mathrm{n}=17,17 \%)$

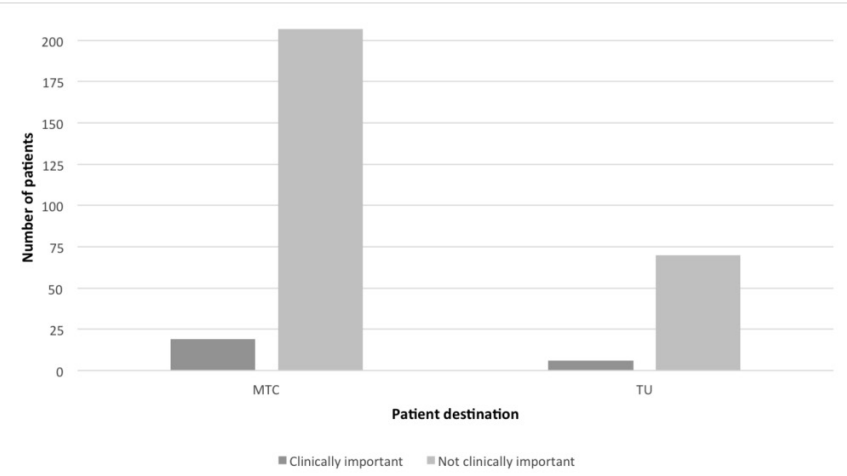

Figure 2 Triage of clinically important patients to major trauma centres or trauma centres. MTC, major trauma centre; TU, trauma centre. Values are number of patients. No statistical relationship was shown between the two groups $\mathrm{p}=0.888$. $(\mathrm{p}=0.01)$, however, there was no significant difference between clinically important brain injury (9\% vs $6 \%$, $\mathrm{p}=0.46$ ).

In the Assist group, no patients deteriorated on route to hospital while in the care of the ambulance service.

\section{Emergency anaesthesia}

Nineteen patients $(6 \%)$ underwent emergency anaesthesia by the HEMS team and of these 12 were found to have an abnormal CT and six a clinically important brain injury. Patients undergoing pre-hospital RSI were significantly more likely to have both an abnormal CT head $(\mathrm{p}=0.01)$ and a clinically important brain injury $(\mathrm{p}=0.03)$ (figure 1).

On secondary analysis, 12 patients underwent RSI for indications related to head injury (cerebral agitation making the patient unmanageable, low GCS or airway compromise due to primary head injury). In these patients, 10 patients had abnormal CT scans and six had clinically important injuries.

The remaining seven patients were RSI'd because the HEMS team felt it was indicated due to other injuries the patient had suffered. Of all patients who underwent RSI by the HEMS team, two required two attempts at laryngoscopy prior to intubation, all others were intubated on first attempt.

A proportion of patients who were not RSI'd by the HEMS team required RSI in the ED after arrival (18), with a higher rate seen in the escorted patients $(7 \%$ vs $2 \%, \mathrm{p}=0.061$ ). Of the patients who received RSI in the ED, 12 had abnormal CT head scans and of these five had clinically important brain injuries.

\section{Triage of patients with clinically important injuries}

Patients that were clinically important $(n=25)$ were transferred to an MTC in $80 \%$ of cases. The majority of non-RSI'd patients who were not clinically important $(\mathrm{n}=277,74 \%)$ were also conveyed to an MTC (figure 2). There was no relationship seen in the triage of patients and where they were transported to, based on neurosurgical importance $(\mathrm{p}=0.888)$.

Of the six patients taken to a TU and subsequently deemed to have a clinically important brain injury, two had extradural haematomas, two were less than 16 years of age, four had a GCS 15 and two a GCS of 14. In five of the six patients, hospital outcome data were available. Four were discharged neurologically intact from hospital within 6-8 days; the final patient died while in hospital after a decision was made to manage conservatively due to other pre-existing co-morbidities.

\section{DISCUSSION}

Minor head injury affects a large number of patients whose mortality is small $(0.1 \%)$ and early morbidity is low $(10 \%) .{ }^{11}$ However, as previously described, ${ }^{9}$ a small number of these patients will have serious intracranial injury and indeed some of these patients will 
appropriately require pre-hospital RSI. This study on a mixed urban and rural UK population supports these findings but also provides context about the decision of who should receive pre-hospital RSI and whether those who are not anaesthetised should be transported directly to a neurosurgical-capable hospital.

Given the high rate of intracranial injury observed in the group who received RSI for an indication related to their head injury (83\%) an important finding of this study is that patients selected to receive RSI by the enhanced care HEMS team are highly likely to have intracranial injury. However, $7 \%$ of those escorted to hospital by the HEMS team awake subsequently received RSI by the receiving team in $\mathrm{ED}$, which warrants consideration of whether these patients may have benefited from pre-hospital anaesthesia. The decision to undertake an RSI in a head injured patient with a relatively well-maintained GCS will depend, in both the pre-hospital setting and the $\mathrm{ED}$, on several factors and on each occasion will require an assessment of the risk versus benefit balance. Patients transferred awake after assessment by the HEMS team but subsequently intubated in ED, may reflect a difference in the risk-benefit assessment by the pre-hospital and ED team, evolving pathology or the different priorities in clinical care required when attempting to perform in-hospital imaging versus pre-hospital transport rather than an inappropriate decision made by the pre-hospital team. However, further research into this area would be valuable.

In this study we report the challenges in the triage of patients with minor head injury who do not require pre-hospital emergency anaesthesia. ${ }^{12}$ With the instigation of regional trauma networks in the UK in 2012, trauma patients are treated within a 'hub and spoke' network. In these, the specialised polytrauma services (including neurosurgery) are located in the 'hub' MTCs. Patients most likely to benefit from transport to the MTC are those with intracranial injury that may require specialist neurosurgical care while conversely, saturation of a limited resource might be threatened by triage of patients who could be managed at a less specialist centre.

The challenge of recognising those patients with a significant intracranial injury in those with a maintained GCS is highlighted by three aspects of our study. First, regarding potential over triage, in our cohort although $76 \%$ of patients were conveyed to an MTC, the majority $(73 \%)$ had normal CT head scans reported at hospital. This apparent over triage may be attributable to a patient set that has likely suffered other insults influencing the attending team's decision. Second, in patients triaged to a TU, a small proportion were found to have a clinically important brain injury. Importantly, while under triage has been noted to be relatively common in major trauma and head injury ${ }^{13}$ and that it may have a significant impact on patient outcome with reported mortality increased by $25 \%$ for major trauma, ${ }^{14}$ no harm was demonstrated as a result of the triage decision in this study. Finally, we found similar rates of those we defined as having the most significant brain injury ('clinically important brain injury') in those that the HEMS team chose to escort to hospital and those transferred by the ambulance service alone.

Given the challenges in accurately differentiating the extent of intra-cranial injury in those patients deemed not requiring RSI, the outcomes of those transferred to TUs but subsequently being found to have significant brain injury, and the lack of deterioration en route to hospital found is reassuring.

This study has certain limitations worthy of comment. Perhaps most importantly, we recognise the low rate of follow-up of the patients not conveyed with the HEMS team. While the clinically important brain injury rate in this group (6\%) bears comparison with other published data, ${ }^{10}$ this missing data may hide a proportion of patients with significant brain injury and hence makes it hard to draw firm comparisons with the other groups in our study.

Additionally, the definition of clinically important brain injury does not necessarily define a group of patients who are certain to benefit from care within a neurosurgical centre. Notably, a recent pan London Major Trauma System audit revealed $65 \%$ of those with significant brain injury are currently managed in a $\mathrm{TU},{ }^{14}$ undergoing CT imaging of the brain as prompted by National Institute for Health and Care Excellence guidance and referred to and discussed with neurosurgeons at the MTC as appropriate. ${ }^{1}$ The majority of these patients remain looked after by non-neurosurgical specialists in the TU. Adequate follow-up data for which patients received a neurosurgical intervention was not available, but again, it seems likely that this will be markedly smaller than those we have defined as clinically important.

\section{CONCLUSION}

In this retrospective review of patients attended by a UK HEMS service with a head injury and GCS of 13-15, a small but significant proportion had a clinically important brain injury. A doctor-paramedic HEMS team can appropriately recognise patients with neurotrauma requiring prehospital anaesthesia. For patients deemed not to need a HEMS intervention, differentiating between those with and without clinically important brain injury appears more challenging, highlighting the difficulties of on-scene triage decisions.

Contributors DB, CR and JWB were involved in data collation and analysis. Data analysis was reviewed by RL. All authors were involved with preparation of the manuscript. All authors approved the manuscript prior to submission.

Funding The authors have not declared a specific grant for this research from any funding agency in the public, commercial or not-for-profit sectors.

Competing interests $\mathrm{DB}, \mathrm{CR}$ and RL are all employees of Kent, Surrey and Sussex Air Ambulance Trust.

Patient consent for publication Not required.

Ethics approval This study met UK National Institute for Health Research criteria for a service evaluation. All the data used for this study were routinely collected as part of standard prehospital and hospital patient data collection. Formal ethical 
approval was therefore waived as criteria for service evaluation were met. The study was registered with the University of Surrey as a service evaluation.

Provenance and peer review Not commissioned; externally peer reviewed.

Data sharing statement All data generated or analysed during this study are included in this published article.

Open access This is an open access article distributed in accordance with the Creative Commons Attribution Non Commercial (CC BY-NC 4.0) license, which permits others to distribute, remix, adapt, build upon this work non-commercially, and license their derivative works on different terms, provided the original work is properly cited, appropriate credit is given, any changes made indicated, and the use is non-commercial. See: http://creativecommons.org/licenses/by-nc/4.0/.

\section{REFERENCES}

1. NICE. Head injury: assessment and early management. 2014.

2. Evaluation of traumatic brain injury, acute. BMJ Best Practice 2016.

3. Borczuk P. Predictors of intracranial injury in patients with mild head trauma. Ann Emerg Med 1995;25:731-6.

4. Vos PE, Alekseenko Y, Battistin L, et al. Mild traumatic brain injury. Eur J Neurol 2012;19:191-8.
5. Rockswold GL, Leonard PR, Nagib MG. Analysis of management in thirty-three closed head injury patients who "talked and deteriorated". Neurosurgery 1987;21:51-5.

6. Mendelow AD, Karmi MZ, Paul KS, et al. Extradural haematoma: effect of delayed treatment. Br Med J 1979;1:1240-2.

7. Nicholl JP, Brazier JE, Snooks HA. Effects of London helicopter emergency medical service on survival after trauma. $B M J$ 1995;311:217-22.

8. Carr BG, Caplan JM, Pryor JP, et al. A meta-analysis of prehospital care times for trauma. Prehosp Emerg Care 2006;10:198-206.

9. Ellis DY, Davies GE, Pearn J, et al. Prehospital rapid-sequence intubation of patients with trauma with a Glasgow Coma Score of 13 or 14 and the subsequent incidence of intracranial pathology. Emerg Med J 2007;24:139-41.

10. Stiell IG, Wells GA, Vandemheen K, et al. The Canadian CT head rule for patients with minor head injury. Lancet 2001;357:1391-6.

11. Shukla D, Devi BI. Mild traumatic brain injuries in adults. J Neurosci Rural Pract 2010;1:82-8.

12. Xiang $\mathrm{H}$, Wheeler $\mathrm{KK}$, Groner $\mathrm{Jl}$, et al. Undertriage of major trauma patients in the US emergency departments. Am J Emerg Med 2014:32:997-1004

13. Haas B, Gomez D, Zagorski B, et al. Survival of the fittest: the hidden cost of undertriage of major trauma. J Am Coll Surg 2010;211:804-11.

14. Wilson M Al. Traumatic injury to the brain across London (TrIBAL). London: Centre for Trauma Sciences, 2016. 